\title{
25 Research Square \\ Fabrication and Detailed Characterization of Perlite Mineral Supported a New Magnetic Nanomaterial.
}

\section{Sinan KUTLUAY}

Siirt University

Ömer ŞAHIN

Siirt University

MEHMET ŞAKIR ECE ( $\nabla$ sakirece@artuklu.edu.tr)

Mardin Artuklu University https://orcid.org/0000-0002-9411-314X

\section{Research Article}

Keywords: Characterization, Magnetic nano particles design, Magnetite, Perlite, Silica, Sol-gel, Surface coating

Posted Date: July 21 st, 2021

DOl: https://doi.org/10.21203/rs.3.rs-722454/v1

License: (9) This work is licensed under a Creative Commons Attribution 4.0 International License. Read Full License 


\section{Abstract}

Today, the possibilities offered by nanotechnology are undeniable. Nanotechnology has permeated all aspects of our daily lives. Nanotechnology, as an interdisciplinary field, also provides unique products in a variety of engineering fields. These products are more appealing than macro products due to their unique properties such as surface area, volume, conductivity, optical, and magnetic. Magnetite $\left(\mathrm{Fe}_{3} \mathrm{O}_{4}\right)$, the most powerful magnetic mineral on the planet, has many properties such as nano size, surface area, morphology, and ferromagnetism at room temperature, and thus $\mathrm{Fe}_{3} \mathrm{O}_{4}$-based products are being developed for appropriate studies. There are very few materials created by modifying perlite $\mathrm{Fe}_{3} \mathrm{O}_{4}, \mathrm{a}$ mineral abundant in nature. In this study, $\mathrm{Fe}_{3} \mathrm{O}_{4}$ was modified with the mineral perlite to create magnetic nanomaterials. To that end, $\mathrm{Fe}_{3} \mathrm{O}_{4} /$ Perlite magnetic nanomaterials were created using a co-precipitation method, followed by $\mathrm{Fe}_{3} \mathrm{O}_{4} /$ Perlite@ $\mathrm{SiO}_{2}$ magnetic nanomaterials created using a sol-gel method, and

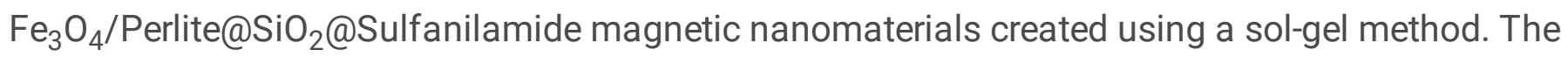
structures of the synthesized magnetic nano materials were clarified by various characterization devices such as BET, FTIR, SEM, SEM-EDX, TGA-DTA, and XRD. The characterization findings revealed that the syntheses and surface coatings of $\mathrm{Fe}_{3} \mathrm{O}_{4} / \mathrm{Perlite}, \mathrm{Fe}_{3} \mathrm{O}_{4} / \mathrm{Perlite} @ \mathrm{SiO}_{2}$ and $\mathrm{Fe}_{3} \mathrm{O}_{4} /$ Perlite@SiO ${ }_{2} @ S$ ulfanilamide magnetic nanomaterials were successfully performed. Furthermore, in light of these findings, $\mathrm{Fe}_{3} \mathrm{O}_{4} / \mathrm{Perlite} \mathrm{Fe}_{3} \mathrm{O}_{4} /$ Perlite@ $\mathrm{SiO}_{2}$ and $\mathrm{Fe}_{3} \mathrm{O}_{4} /$ Perlite@SiO ${ }_{2} @ S u l f a n i l a m i d e$ magnetic nano materials were discovered to be in crystalline cubic spinel form, mechanical and thermal stability, and mesoporic size. Since synthesized perlite-supported magnetic nano materials have potential in many applications, such as sustainable technologies, environmental safety technologies such as water reclamation and pollution removal, adsorption technologies, etc., they are brought to the attention of related fields.

\section{Highlights}

- $\mathrm{Fe}_{3} \mathrm{O}_{4} /$ Perlite magnetic nano materials were fabricated from $\mathrm{Fe}^{+2}, \mathrm{Fe}^{+3}$ and Perlite by co-precipitation method.

- Core@shell $\left(\mathrm{Fe}_{3} \mathrm{O}_{4} /\right.$ Perlite@ $\left.\mathrm{SiO}_{2}\right)$ was carried out by the sol-gel method.

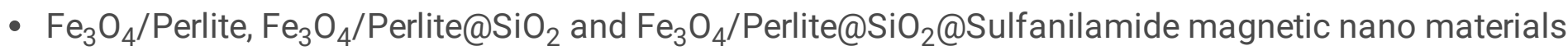
were successfully fabricated.

- Perlite provided thermal stability to the structure.

- $\mathrm{Fe}_{3} \mathrm{O}_{4} /$ Perlite, $\mathrm{Fe}_{3} \mathrm{O}_{4} /$ Perlite@SiO $\mathrm{S}_{2}$ and $\mathrm{Fe}_{3} \mathrm{O}_{4} /{\mathrm{Perlite} @ \mathrm{SiO}_{2} @ S u l f a n i l a m i d e}$ magnetic nano materials have mesoporous structure.

- These magnetic nano materials could be a promising candidate for sustainable technologies.

\section{Introduction}


Nanotechnology, which deals with materials on a scale of 1 to $100 \mathrm{~nm}$, is a rapidly growing branch of science with significant applications in materials science. Nano materials have recently received a lot of attention because of their fascinating structural (magnetic, optical, electrical, and so on) behavior. Nano materials research has been a popular topic over the last two decades. Nanostructured materials such as nanofilms, nanotubes, and nanocomposites have been developed for use in a wide range of applications. With dizzying recent advances in materials science, nano materials with advanced compositions, adjustable surface charges, shapes, morphologies, well-characterized dimensions, and physicochemical properties are now produced/synthesized. Nano materials are widely acknowledged as the foundation of nano engineering and nano science. Because of their complementary properties and unique structure in comparison to other materials, nano materials are promising materials (Kalambate, Huang et al. 2019).

Non-toxic magnetite $\left(\mathrm{Fe}_{3} \mathrm{O}_{4}\right)$ is a widely used magnetic nano material in materials science that is of academic interest because of its availability, reusability, and ease of isolation under an external magnetic field, as well as its bio-physicochemical compatibility. $\mathrm{Fe}_{3} \mathrm{O}_{4}$ is an iron oxide with a cubic inverted spinel structure. It contains Fe cations in the interstitial tetrahedral and octahedral sites, as well as cubic closed packed oxygen anions (Abdullah, Shameli et al. 2017). $\mathrm{Fe}_{3} \mathrm{O}_{4}$ with exceptional properties Magnetism has a lot of surface energy. Agglomeration of $\mathrm{Fe}_{3} \mathrm{O}_{4}$ is caused by high surface energy. However, $\mathrm{Fe}_{3} \mathrm{O}_{4}$ has a high level of chemical activity. $\mathrm{Fe}_{3} \mathrm{O}_{4}$ oxidizes in the air due to its high chemical activity. Agglomeration and oxidation reduce the magnetism and dispersibility of $\mathrm{Fe}_{3} \mathrm{O}_{4}$. In order to obtain yield from bare $\mathrm{Fe}_{3} \mathrm{O}_{4}$, it must be functionalized with various materials. Functionalization provides $\mathrm{Fe}_{3} \mathrm{O}_{4}$ with areas of chemical coordination/conjugation and chemical stability (Shen, Li et al. 2018).

Because it is natural, perlite, an industrial and glassy volcanic mineral, is environmentally friendly. It can expand up to 35 times its internal volume at high temperatures $\left(850-1100^{\circ} \mathrm{C}\right)$. It has a low density as well as a low thermal conductivity. It contains a high concentration of silica (more than 70 percent). Perlite has an adsorptive character due to the presence of silanol atoms. Depending on the $\mathrm{pH}$ of the solution medium, it can be charged (+) or (-). It can be used as a filler in a variety of processes and materials due to its chemical ineffectiveness in many environments. It is used in a variety of industries, including dam cleaning, the food industry, clear water extraction, the iron and steel industry, construction, the metal industry, and agriculture (Acemioğlu 2005). Perlite, an aluminosilicate, is a low-cost mineral with an amorphous structure and high availability. Low cost, environmental friendliness, lack of toxic, fireresistance, high surface area, high water content (in addition to water, $\mathrm{Al}_{2} \mathrm{O}_{3}$ and $\mathrm{SiO}_{2}$, also $\mathrm{K}_{2} \mathrm{O}, \mathrm{Na}_{2} \mathrm{O}$, $\mathrm{Cao}, \mathrm{MGO}, \mathrm{TiO}_{2}, \mathrm{MnO}_{2}, \mathrm{SO}_{3}$ ), chemical inertness, and lightness perlite are some distinguishing characteristics. Mechanical and thermal stability are high in perlite-based composites (Jafarirad, Pooresmaeil et al. 2021).

Functionalizing magnetic nano materials with silica $\left(\mathrm{SiO}_{2}\right)$ facilitates operation while also contributing to the advancement of magnetic nano materials in materials science. $\mathrm{SiO}_{2}$ prevents magnetic dipolar attraction and agglomeration in $\mathrm{Fe}_{3} \mathrm{O}_{4}$, allows $\mathrm{Fe}_{3} \mathrm{O}_{4}$ to be easily dispersed in liquid media, and protects $\mathrm{Fe}_{3} \mathrm{O}_{4}$ in acidic media. Silanol groups activate the surface of $\mathrm{SiO}_{2}$-coated magnetic nano materials for 
various functional groups and solidify the surface. The silica layer provides a chemical-inert surface for magnetic nano materials in biological systems because of these benefits. Because of its relatively mild reaction conditions, low cost, and lack of surfactant, the sol-gel method is preferred in many techniques for coating $\mathrm{Fe}_{3} \mathrm{O}_{4}$ with $\mathrm{SiO}_{2}$ (Deng, Wang et al. 2005).

Sulfanilamide is a simple organic sulfur compound. This organic compound contains two $\mathrm{NH}_{2}$ and one $\mathrm{SO}_{2}$ groups (Ece 2021). Sulfanilamide is used in the prevention and treatment of bacterial infections as an antimicrobial antifolic agent. Because of their pharmacological activity, sulfanilamide and its derivatives have received a lot of attention in biology (supramolecular) and medicine (antiviral, antifungal, antitumor, anti-inflammatory). They are successfully used in clinics due to their excellent pharmacological activity (Wang, Wan et al. 2010).

The manufacture of magnetic nano materials supplemented with perlite is almost non-existent in the literature. Perlite was added to $\mathrm{Fe}_{3} \mathrm{O}_{4}$ in this study. The surface of the $\mathrm{Fe}_{3} \mathrm{O}_{4}$ /perlite was then coated with $\mathrm{SiO}_{2}$. Sulfanilamide was eventually used to modify $\mathrm{Fe}_{3} \mathrm{O}_{4} /$ Perlite@SiO 2 . BET, FTIR, SEM, SEM-EDX, TGADTA, and XRD analyses were used to characterize $\mathrm{Fe}_{3} \mathrm{O}_{4} /$ Perlite, $\mathrm{Fe}_{3} \mathrm{O}_{4} /$ Perlite@SiO ${ }_{2}$, and

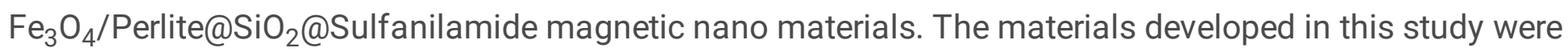
presented to the materials science community in order to capitalize on their biological, chemical, and physical advantages.

\section{Materials And Methods}

\subsection{Chemicals and reagents}

Iron (II) chloride tetrahydrate $\left(\mathrm{FeCl}_{2} \cdot 4 \mathrm{H}_{2} \mathrm{O}\right)$, Tetraethyl orthosilicate (TEOS, $\left.\mathrm{Si}\left(\mathrm{OC}_{2} \mathrm{H}_{5}\right)_{4}\right)$ was supplied from Alpha Aesar, Iron (III) chloride hexahydrate $\left(\mathrm{FeCl}_{3} .6 \mathrm{H}_{2} \mathrm{O}\right)$ from Merck, ammonia $\left(\mathrm{NH}_{3}\right)$ from VWR chemicals, Sulfanilamide $\left(\mathrm{C}_{6} \mathrm{H}_{8} \mathrm{~N}_{2} \mathrm{O}_{2} \mathrm{~S}\right)$ and ethanol $\left(\mathrm{CH}_{3} \mathrm{CH}_{2} \mathrm{OH}\right)$ from Sigma-Aldrich. The chemicals and reagents used in this study are of standard analytical purity. Perlite $(+355,-500$ mesh) powder was obtained from Bitlis-Turkey perlite mine.

\subsection{Fabrication processes}

\subsubsection{Fabrication of $\mathrm{Fe}_{3} \mathrm{O}_{4} /$ Perlite magnetic nano material}

$\mathrm{Fe}_{3} \mathrm{O}_{4} /$ Perlite magnetic nano material was fabricated by co-deposition. Each stage of the reaction was carried out under inert medium (argon gas). At $80^{\circ} \mathrm{C}, 6 \mathrm{~g}$ perlite was filtered in $100 \mathrm{~mL}$ ethanol for $30 \mathrm{~min}$, sufficiently expanded volume, left in a mixture of $2 \mathrm{mmol} \mathrm{FeCl}_{3} \cdot 6 \mathrm{H}_{2} \mathrm{O}$ and $4 \mathrm{mmol} \mathrm{FeCl} \cdot 4 \mathrm{H}_{2} \mathrm{O}$ distributed in $100 \mathrm{~mL}$ deionized water, and mixed at $80^{\circ} \mathrm{C}$ for $30 \mathrm{~min}$ at $1000 \mathrm{rpm}$. For co-precipitation to occur, a drop of $10 \mathrm{~mL}$ of $8 \mathrm{~m} \mathrm{NH}_{3}$ solution was added to the reaction system. After continuing the reaction for 30 $\mathrm{min}$, the reaction system was turned off and allowed to cool. Magnetic nano particles of brownish black $\mathrm{Fe}_{3} \mathrm{O}_{4} / \mathrm{Perlite}$ (Perlite/ $\mathrm{Fe}=9$ ) were obtained. To remove unreacted chemicals, the resulting $\mathrm{Fe}_{3} \mathrm{O}_{4} / \mathrm{Perlite}$ 
magnetic nano particles were washed several times with distilled water and ethyl alcohol. Magnetic separation was used to isolate $\mathrm{Fe}_{3} \mathrm{O}_{4} /$ Perlite magnetic nano material. The product was dried (Ahmed, Hamed et al. 2020).

\subsubsection{Fabrication of $\mathrm{Fe}_{3} \mathrm{O}_{4} /$ Perlite@SiO ${ }_{2}$ magnetic nano material}

$\mathrm{Fe}_{3} \mathrm{O}_{4} /$ Perlite@SiO 2 magnetic nano material was fabricated by sol-gel method. Each stage of the reaction was carried out under inert medium (argon gas). $1 \mathrm{~g}$ of $\mathrm{Fe}_{3} \mathrm{O}_{4} /$ Perlite magnetic nano material placed in the reaction bottle were sonicated in $100 \mathrm{~mL}$ of ethanol and $50 \mathrm{~mL}$ of deionized water. Drop by drop, 30 $\mathrm{mL} 8 \mathrm{M} \mathrm{NH}_{3}$ and 4 mmol TEOS were added to the mixture. The reaction system was turned off after $12 \mathrm{~h}$ of mixing in room temperature. The resulting $\mathrm{Fe}_{3} \mathrm{O}_{4} /$ Perlite@SiO $\mathrm{S}_{2}$ magnetic nano material was cleaned with ethanol and deionized water. Magnetic separation was used to isolate $\mathrm{Fe}_{3} \mathrm{O}_{4} / \mathrm{Perlite}_{\mathrm{SSiO}}$ magnetic nano material. The product was dried (Ece 2021).

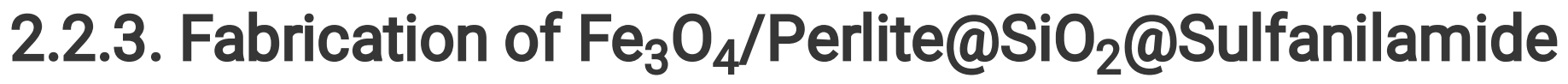 magnetic nano material}

Each stage of the reaction was performed in an inert medium (argon gas). $1 \mathrm{~g}$ of $\mathrm{Fe}_{3} \mathrm{O}_{4} /{\mathrm{Perlite} @ S i \mathrm{~S}_{2}}$ magnetic nano material was added to a reaction bottle with $200 \mathrm{~mL}$ of ethanol and sonicated. The reaction bottle was then filled with $2 \mathrm{~g}$ Sulfanilamide and refluxed for $15 \mathrm{~h}$. The reaction system was turned off, and the system was allowed to cool. The $\mathrm{Fe}_{3} \mathrm{O}_{4} / \mathrm{Perlite@SiO_{2 } @ S u l f a n i l a m i d e ~ m a g n e t i c ~ n a n o ~}$ material that resulted were washed with ethanol and deionized water, respectively. Magnetic separation

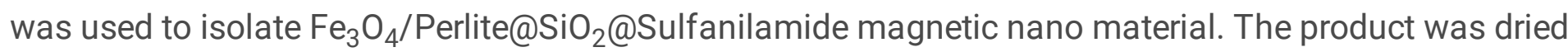
(Ghorbani-Choghamarani, Shiri et al. 2016). The fabrication processes of magnetic nano materials are schematically presented in Fig. 1, and the magnetization abilities of magnetic nano materials are presented in Fig. 2.

\subsection{Characterizations}

The characterization of magnetic nano adsorbents was carried out by scanning electron microscopy (SEM) and energy-distributed X-ray spectroscopy (EDX) analysis, Fourier Transform Infrared Spectroscopy (FTIR), X-ray Diffraction Spectrometer (XRD), differential thermal analysis (DTA), thermal gravimetric analysis (TGA), Brunauer-Emmett-Teller (BET) surface area analysis. The synthesized magnetic nano materials were characterized by SEM (ZEISS, EVO 50 Series, Carl Zeiss AG, Jena, Germany) for morphological structure analysis. The basic element components of magnetic nano materials were determined by EDX (Bruker, Quantax EDsingle bondXS, Bruker AXS GmbH, Karlsruhe, Germany). The surface properties of magnetic nano materials were analyzed using the FTIR spectrometer (Bruker, Vertex 70v, Bruker Optics Inc., Billerica, USA). FTIR spectra were obtained using the transmission technique (analysis range: $4000-400 \mathrm{~cm}^{-1}$ wave numbers). The phase structure and crystallization of magnetic nano materials was characterized by the XRD (D/MAX 2200, Rigaku Corp., Japan) and 
Brunauer-Emmett-Teller (BET, Quantachrome, Nova 2200E, Quantachrome GmbH \& Co. KG, Odelzhausen, Germany). TGA and DTA were performed for the creation of magnetic nano materials and the determination of quantitative differences of surface-bound functional groups. TGA and DTA thermograms were obtained with a TG/DTA simultaneous measuring device (SHIMADZU, DTG-60, Shimadzu Europa $\mathrm{GmbH}$, Duisburg, Germany) at a heating rate of $10^{\circ} \mathrm{C} / \mathrm{min}$ in the range of $25-1000^{\circ} \mathrm{C}$. Surface area measurements of magnetic nano materials were performed at $77 \mathrm{~K}$ according to the nitrogen adsorption/desorption method of BET (Quantachrome, Nova 2200E, Quantachrome GmbH \& Co. KG, Odelzhausen, Germany).

\section{Results And Discussions}

\subsection{Characterization of magnetic nanomaterials}

$\mathrm{Fe}_{3} \mathrm{O}_{4} /$ Perlite, $\mathrm{Fe}_{3} \mathrm{O}_{4} /$ Perlite@SiO ${ }_{2}$ and $\mathrm{Fe}_{3} \mathrm{O}_{4} /$ Perlite@SiO ${ }_{2} @ S$ ulfanilamide magnetic nano materials were characterized in detail by BET, FTIR, SEM, SEM-EDX, TGA-DTA and XRD analysis techniques.

\subsubsection{SEM analysis}

SEM images of the surface morphologies of $\mathrm{Fe}_{3} \mathrm{O}_{4} /$ Perlite, $\mathrm{Fe}_{3} \mathrm{O}_{4} /$ Perlite@SiO $\mathrm{O}_{2}$ and $\mathrm{Fe}_{3} \mathrm{O}_{4} / \mathrm{Perlite} @ \mathrm{SiO}_{2} @ S$ ulfanilamide magnetic nano materials are presented in Fig. 3. Figure 3a shows that the regular/homogeneous appearance of $\mathrm{Fe}_{3} \mathrm{O}_{4}$ /Perlite magnetic nano materials similar to a wooden stick/leaf is smooth, with dense, wide and deep cavities/pores. Figure $3 \mathrm{~b}$ depicts that $\mathrm{Fe}_{3} \mathrm{O}_{4} /{\mathrm{Perlite} @ \mathrm{SiO}_{2}}$ magnetic nano materials have irregular and rough shapes when compared to $\mathrm{Fe}_{3} \mathrm{O}_{4} /$ Perlite magnetic nano materials, resulting in fewer dense, wide, and deep cavities. It is believed that $\mathrm{SiO}_{2}$ surrounds $\mathrm{Fe}_{3} \mathrm{O}_{4}$ /Perlite magnetic nano materials with light-colored spherical beads, revealing the material's coreshell layered structure. It is observed in Fig. $3 c$ that the dense, wide and deep cavities on the surface of $\mathrm{Fe}_{3} \mathrm{O}_{4} / \mathrm{Perlite} @ \mathrm{SiO}_{2} @ S$ ulfanilamide magnetic nano materials are close to disappearing, and the residue

of irregularity and smoothness dominates the surface in the form of lighter spherical beads thanks to the surfactant functional group (Sulfanilamide). The results confirm that $\mathrm{SiO}_{2}$ coated $\mathrm{Fe}_{3} \mathrm{O}_{4} / \mathrm{Perlite}$, then sulfanilamide coated $\mathrm{Fe}_{3} \mathrm{O}_{4} /$ Perlite@ $\mathrm{SiO}_{2}$.

\subsubsection{SEM-EDX analysis}

The SEM-EDX analyses of the basic element components of $\mathrm{Fe}_{3} \mathrm{O}_{4} /$ Perlite, $\mathrm{Fe}_{3} \mathrm{O}_{4} /$ Perlite@SiO ${ }_{2}$ and $\mathrm{Fe}_{3} \mathrm{O}_{4} / \mathrm{Perlite} @ \mathrm{SiO}_{2} @ S$ ulfanilamide magnetic nano materials are shown in Fig. 4, Fig. 5 and Fig. 6, respectively. As expected in $\mathrm{Fe}_{3} \mathrm{O}_{4} /$ Perlite and $\mathrm{Fe}_{3} \mathrm{O}_{4} /$ Perlite@SiO $\mathrm{O}_{2}$ magnetic nano materials, $\mathrm{Al}, \mathrm{Ca}, \mathrm{Fe}, \mathrm{K}$, Mg, Mn, Na, O, S, Si, Ti elements were observed. Similarly, in $\mathrm{Fe}_{3} \mathrm{O}_{4} /$ Perlite@SiO ${ }_{2} @ S$ ulfanilamide magnetic nano material, $\mathrm{Al}, \mathrm{C}, \mathrm{Ca}, \mathrm{Fe}, \mathrm{K}, \mathrm{Mg}, \mathrm{Mn}, \mathrm{N}, \mathrm{Na}, \mathrm{O}, \mathrm{S}, \mathrm{Si}$, Ti elements were observed. The results confirm the successful fabrication of $\mathrm{Fe}_{3} \mathrm{O}_{4} / \mathrm{Perlite}, \mathrm{Fe}_{3} \mathrm{O}_{4} / \mathrm{Perlite} @ \mathrm{SiO}_{2}$ and $\mathrm{Fe}_{3} \mathrm{O}_{4} /$ Perlite@SiO ${ }_{2} @ S$ ulfanilamide magnetic nano materials. 


\subsubsection{FTIR analysis}

The FTIR spectra of $\mathrm{Fe}_{3} \mathrm{O}_{4} /$ Perlite, $\mathrm{Fe}_{3} \mathrm{O}_{4} /$ Perlite@SiO $\mathrm{S}_{2}$ and $\mathrm{Fe}_{3} \mathrm{O}_{4} /$ Perlite@SiO $\mathrm{O}_{2} @$ Sulfanilamide magnetic nano materials are presented in Fig. 7. In all three materials, the peak around $564 \mathrm{~cm}^{-1}$ is a square peak indicating the presence of $\mathrm{Fe}_{3} \mathrm{O}_{4}$ caused by the $\mathrm{Fe}-\mathrm{O}$ bond (Ece 2021, Kutluay 2021). Peak around 800 $\mathrm{cm}^{-1}$ is a symmetrical stress peak showing the Si-O-Si bond. A wide and sharp peak around $1082 \mathrm{~cm}^{-1}$ is an asymmetric stress peak indicating the presence of a Si-O-Si bond. Peak around $1652 \mathrm{~cm}^{-1}$ is a bending stress peak indicating the presence of an $\mathrm{O}-\mathrm{H}$ bond. The peak around $3330 \mathrm{~cm}^{-1}$ is the tensile peak of single bond $\mathrm{OH}$ groups of different structures, such as $\mathrm{H}-\mathrm{OH}, \mathrm{Al}-\mathrm{OH}$, and $\mathrm{Si}-\mathrm{OH}$, adsorbed to the surface. The peaks observed in the FTIR spectrum of $\mathrm{Fe}_{3} \mathrm{O}_{4} /$ Perlite@SiO $\mathrm{O}_{2} @$ Sulfanilamide magnetic nano material at $1490 \mathrm{~cm}^{-1}$ indicate the presence of the $\mathrm{N}-\mathrm{H}$ bond. The symmetrical and asymmetric stretching peaks of $\mathrm{O}=\mathrm{S}=0$, which are expected to be seen at $1140 \mathrm{~cm}^{-1}$ and $1325 \mathrm{~cm}^{-1}$, are covered by other peaks, respectively. The peak observed at $1410 \mathrm{~cm}^{-1}$ shows $C=C$ aromatic, and the peak observed at $2910 \mathrm{~cm}^{-1}$ shows $\mathrm{CH}_{2}$ vibrations. The findings are consistent with the literature (Ahmed, Hamed et al. 2020, Ece 2021). The results obtained confirm that $\mathrm{Fe}_{3} \mathrm{O}_{4} / \mathrm{Perlite}, \mathrm{Fe}_{3} \mathrm{O}_{4} / \mathrm{Perlite} @ \mathrm{SiO}_{2}$ and

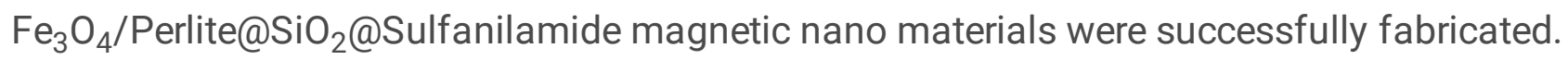

\subsubsection{XRD analysis}

The XRD patterns of $\mathrm{Fe}_{3} \mathrm{O}_{4} /$ Perlite, $\mathrm{Fe}_{3} \mathrm{O}_{4} /$ Perlite@SiO ${ }_{2}$ and $\mathrm{Fe}_{3} \mathrm{O}_{4} /$ Perlite@SiO ${ }_{2} @ S u l f a n i l a m i d e$ magnetic nano materials are shown in Fig. 8. In the XRD model of $\mathrm{Fe}_{3} \mathrm{O}_{4}$ /Perlite magnetic nanomaterial, the observed peaks of $30.52^{0}(220), 35.76^{0}(311), 43.50^{\circ}(400), 51.28^{0}(422), 57.68^{0}(511)$ and $63.18^{0}$ (440) indicate the presence of $\mathrm{Fe}_{3} \mathrm{O}_{4}$ in the structure. In addition, these peaks show the crystalline cubic spinel form. The peak at $24.40^{\circ}$ is the diffraction peak of amorphous $\mathrm{SiO}_{2}$. The observation of these

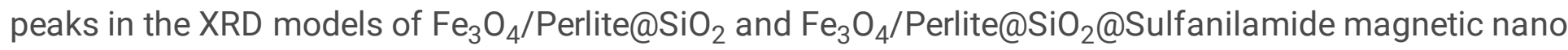
materials shows that the surface coating was successfully achieved, and that $\mathrm{Fe}_{3} \mathrm{O}_{4}$ and $\mathrm{SiO}_{2}$ maintain their form in the coatings (Gad and Elbarbary 2021). In addition, the observed peaks of $15.78^{0}, 30.76^{\circ}$

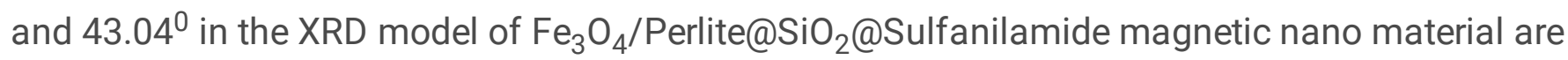
diffraction peaks of Sulfanilamide (Muthuselvi, Gayathri et al. 2016).

\subsubsection{TGA-DTA}

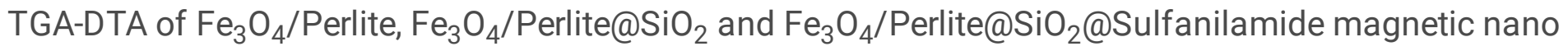
materials are presented in Fig. 9. In TGA analysis, the mass loss of $\mathrm{Fe}_{3} \mathrm{O}_{4} /$ Perlite, $\mathrm{Fe}_{3} \mathrm{O}_{4} / \mathrm{Perlite} @ \mathrm{SiO}_{2}$ ve

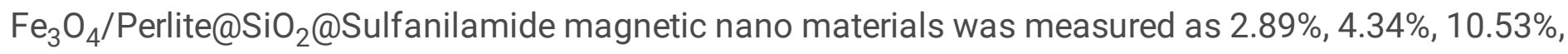
respectively. The mass loss that occurs below $200^{\circ} \mathrm{C}$ is due to evaporation of water molecules and solvents adsorbed to the surface, sublimation of sulfanilamide. Mass loss in the range of $200-600^{\circ} \mathrm{C}$ is due to the extinction of oxygen-carrying groups. However, thermal decomposition and crystal water 
decomposition are thought to occur. The phase change of iron oxides also occurs in this temperature range. At temperatures above $600^{\circ} \mathrm{C}$, very little mass loss indicates high thermal stability (Ece, Kutluay et al. 2020). Exothermic peaks in DTA are caused by incineration of combustible species. However, the exothermic peak around $735^{\circ} \mathrm{C}$ is due to the transformation of $\mathrm{SiO}_{2}$ (Majouli, Younssi et al. 2011).

\subsubsection{BET analysis}

\subsubsection{1. $\mathrm{N}_{2}$ adsorption-desorption isotherms}

$\mathrm{N}_{2}$ adsorption-desorption isotherms of $\mathrm{Fe}_{3} \mathrm{O}_{4} /$ Perlite, $\mathrm{Fe}_{3} \mathrm{O}_{4} /$ Perlite@SiO $\mathrm{S}_{2}$ and $\mathrm{Fe}_{3} \mathrm{O}_{4} /$ Perlite@SiO ${ }_{2} @ S$ ulfanilamide magnetic nano materials are presented in Fig. 10. While the isotherms given in Fig. 10 were examined, it was concluded that $\mathrm{Fe}_{3} \mathrm{O}_{4} / \mathrm{Perlite}, \mathrm{Fe}_{3} \mathrm{O}_{4} / \mathrm{Perlite} @ \mathrm{SiO}_{2}$ and $\mathrm{Fe}_{3} \mathrm{O}_{4} /$ Perlite@SiO ${ }_{2} @ S$ ulfanilamide magnetic nano materials showed type IV-H3 hysteresis cycles according to the IUPAC (International Union of Pure and Applied Chemistry) classification. However, these hysteresis cycles are characteristic of mesoporous materials. The obtained values are compatible with the literature (Bharath, Alhseinat et al. 2017, Cychosz and Thommes 2018).

\subsubsection{BJH pore size distributions}

BJH pore size distributions of $\mathrm{Fe}_{3} \mathrm{O}_{4} /$ Perlite, $\mathrm{Fe}_{3} \mathrm{O}_{4} /$ Perlite@SiO ${ }_{2}$ and $\mathrm{Fe}_{3} \mathrm{O}_{4} /$ Perlite@SiO ${ }_{2} @ S$ ulfanilamide magnetic nano materials are presented in Fig. 11. When $\mathrm{BJH}$ pore size distributions were examined, $\mathrm{Fe}_{3} \mathrm{O}_{4} /$ Perlite, $\mathrm{Fe}_{3} \mathrm{O}_{4} /$ Perlite@SiO ${ }_{2}$ and $\mathrm{Fe}_{3} \mathrm{O}_{4} /$ Perlite@SiO $_{2} @$ Sulfanilamide magnetic nano materials were found to be $9.683 \mathrm{~nm}, 7.912 \mathrm{~nm}, 34.692 \mathrm{~nm}$, respectively. According to the IUPAC Classification ( $2<$

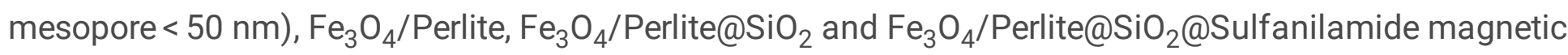
nano materials were found to be included in the meso-pore classification. The values obtained are compatible with the literature (Zhu, Fu et al. 2011, Cuong, Wu et al. 2020).

\subsubsection{DFT pore size distributions}

DFT pore size distributions of $\mathrm{Fe}_{3} \mathrm{O}_{4} /$ Perlite, $\mathrm{Fe}_{3} \mathrm{O}_{4} /$ Perlite@SiO ${ }_{2}$ and $\mathrm{Fe}_{3} \mathrm{O}_{4} /$ Perlite@SiO ${ }_{2} @ S$ ulfanilamide magnetic nano materials are presented in Fig. 12. When examining the dominant pore width,

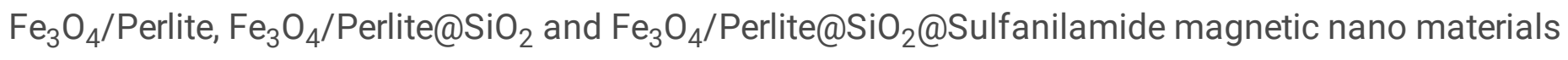
were found to have pore width of $3.917 \mathrm{e}-02 \mathrm{cc} / \mathrm{g}, 5.025 \mathrm{e}-02 \mathrm{cc} / \mathrm{g}$ and $1.022 \mathrm{e}-01 \mathrm{cc} / \mathrm{g}$ respectively. When pore volumes were examined, $\mathrm{Fe}_{3} \mathrm{O}_{4} /$ Perlite, $\mathrm{Fe}_{3} \mathrm{O}_{4} /$ Perlite@SiO ${ }_{2}$ and $\mathrm{Fe}_{3} \mathrm{O}_{4} /$ Perlite@SiO ${ }_{2} @ S$ ulfanilamide magnetic nano materials were found to have pore volumes of $2.271 \mathrm{~nm}, 1.585 \mathrm{~nm}$ and $17.999 \mathrm{~nm}$, respectively (Zhu, Fu et al. 2011, Liu, Zhao et al. 2020).

\subsubsection{Textural properties of the $\mathrm{Fe}_{3} \mathrm{O}_{4} /$ Perlite, $\mathrm{Fe}_{3} \mathrm{O}_{4} /$ Perlite@SiO 2 and}




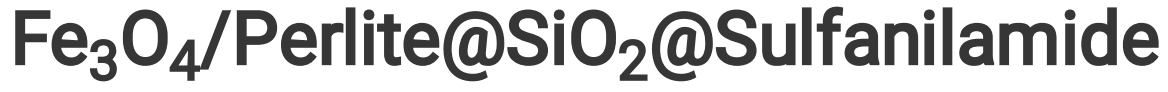

The textural properties of $\mathrm{Fe}_{3} \mathrm{O}_{4} /$ Perlite, $\mathrm{Fe}_{3} \mathrm{O}_{4} /$ Perlite@SiO ${ }_{2}$ and $\mathrm{Fe}_{3} \mathrm{O}_{4} /$ Perlite@SiO ${ }_{2} @ S$ ulfanilamide magnetic nano materials are presented in Table 1. When the textural properties of $\mathrm{Fe}_{3} \mathrm{O}_{4} / \mathrm{Perlite}$,

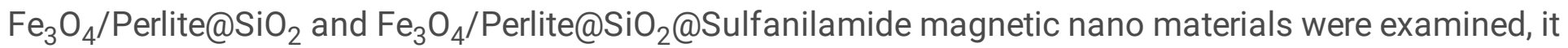
became clear that the $\mathrm{BET}$ surface areas of $\mathrm{Fe}_{3} \mathrm{O}_{4} / \mathrm{Perlite}, \mathrm{Fe}_{3} \mathrm{O}_{4} / \mathrm{Perlite} @ \mathrm{SiO}_{2}$ and

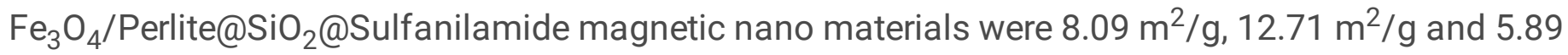
$\mathrm{m}^{2} / \mathrm{g}$, respectively.

Table 1

Textural properties of the $\mathrm{Fe}_{3} \mathrm{O}_{4} /$ Perlite, $\mathrm{Fe}_{3} \mathrm{O}_{4} /$ Perlite@SiO ${ }_{2}$ and $\mathrm{Fe}_{3} \mathrm{O}_{4} / \mathrm{Perlite} @ \mathrm{SiO}_{2} @ S$ Sulfanilamide

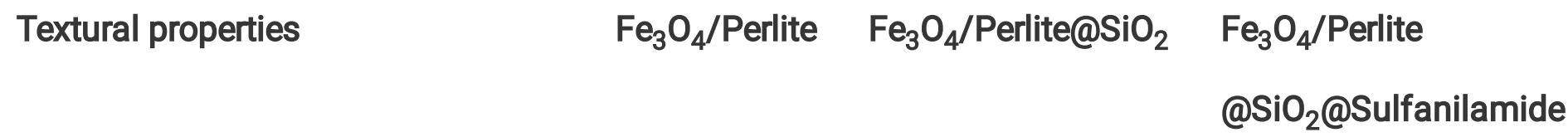

\begin{tabular}{|llll|}
\hline BET surface area $\left(\mathrm{m}^{2} / \mathrm{g}\right)$ & 8.09 & 12.71 & 5.89 \\
\hline Total pore volume $\left(\mathrm{cm}^{3} / \mathrm{g}\right)$ & 0.04 & 0.05 & 0.10 \\
\hline $\begin{array}{l}\text { Mesopore volume } / \text { fraction }(\mathrm{D}-\mathrm{R}) \\
\left(\mathrm{cm}^{3} / \mathrm{g}\right)\end{array}$ & $0.04 / 100 \%$ & $0.05 / 100 \%$ & $0.10 / 100 \%$ \\
\hline Average pore radius $(\mathrm{BJH})(\AA)$ & 96.83 & 79.12 & 346.92 \\
\hline Surface area $(\mathrm{BJH})\left(\mathrm{m}^{2} / \mathrm{g}\right)$ & 8.61 & 10.35 & 7.79 \\
\hline Pore volume $(\mathrm{BJH})\left(\mathrm{cm}^{3} / \mathrm{g}\right)$ & 0.04 & 0.05 & 0.10 \\
\hline Pore radius $(\mathrm{BJH})(\AA)$ & 15.27 & 17.04 & 21.56 \\
\hline Surface area $(\mathrm{DFT})\left(\mathrm{m}^{2} / \mathrm{g}\right)$ & 5.07 & 8.57 & 4.95 \\
\hline Pore volume $(\mathrm{DFT})\left(\mathrm{cm}^{3} / \mathrm{g}\right)$ & 0.03 & 0.04 & 0.05 \\
\hline Half pore width $(\mathrm{DFT})(\AA)$ & 22.71 & 15.85 & 179.99 \\
\hline
\end{tabular}

A comparison of the data leads to a prediction that mesoporous magnetic nano materials with cavity resemble the 3-dimensional structure shown in Fig. 13.

\section{Conclusions}

In this study, $\mathrm{Fe}_{3} \mathrm{O}_{4} /$ Perlite was fabricated by co-precipitation method, then $\mathrm{Fe}_{3} \mathrm{O}_{4} /$ Perlite@SiO ${ }_{2}$ by sol-gel method, $\mathrm{Fe}_{3} \mathrm{O}_{4} / \mathrm{Perlite@SiO_{2 } @ S u l f a n i l a m i d e ~ m a g n e t i c ~ n a n o ~ m a t e r i a l s ~ w e r e ~ f a b r i c a t e d ~ a s ~ t h e ~ f i n a l ~}$ product. The structures of these materials were clarified by various characterization devices. The characterization indicated that the fabrication and surface coatings of $\mathrm{Fe}_{3} \mathrm{O}_{4} / \mathrm{Perlite}, \mathrm{Fe}_{3} \mathrm{O}_{4} / \mathrm{Perlite}_{\mathrm{SiO}}$ 
and $\mathrm{Fe}_{3} \mathrm{O}_{4} / \mathrm{Perlite} @ \mathrm{SiO}_{2} @ S$ Sulfanilamide magnetic nano materials were successful. It was discovered that $\mathrm{Fe}_{3} \mathrm{O}_{4} /$ Perlite, $\mathrm{Fe}_{3} \mathrm{O}_{4} /$ Perlite@SiO ${ }_{2}$ and $\mathrm{Fe}_{3} \mathrm{O}_{4} /$ Perlite@SiO $\mathrm{O}_{2} @ S$ ulfanilamide magnetic nano materials are crystalline cubic spinels with mechanical and thermal stability and a mesoporous size. Successfully fabricated perlite-supported magnetic nano materials can be used in a variety of applications, including sustainable technologies, environmental safety technologies such as water reclamation and pollution removal, and adsorption technologies.

\section{Declarations}

\section{Acknowledgments}

This project is funded by the financial support from Mardin Artuklu University (Project No. MAU.BAP.18.SHMYO.030)

\section{Declaration of Competing Interest}

The authors declare that they have no known competing financial interests or personal relationships that could have appearedto influence the work reported in this paper.

\section{References}

Abdullah, N. H., et al. (2017). "Facile and green preparation of magnetite/zeolite nanocomposites for energy application in a single-step procedure." Journal of Alloys and Compounds 719: 218-226.

Acemioğlu, B. (2005). "Batch kinetic study of sorption of methylene blue by perlite." Chemical Engineering Journal 106(1): 73-81.

Ahmed, I. M., et al. (2020). "Experimental and mathematical modeling of $\mathrm{Cr}$ (VI) removal using nanomagnetic Fe304-coated perlite from the liquid phase." Chinese Journal of Chemical Engineering 28(6): 1582-1590.

Bharath, G., et al. (2017). "Development of adsorption and electrosorption techniques for removal of organic and inorganic pollutants from wastewater using novel magnetite/porous graphene-based nanocomposites." Separation and Purification Technology. 188: 206-218.

Cuong, D. V., et al. (2020). "Hierarchical porous carbon derived from activated biochar as an eco-friendly electrode for the electrosorption of inorganic ions." Separation and Purification Technology_ 242: 116813.

Cychosz, K. A. and M. Thommes (2018). "Progress in the physisorption characterization of nanoporous gas storage materials." Engineering 4(4): 559-566.

Deng, Y.-H., et al. (2005). "Investigation of formation of silica-coated magnetite nanoparticles via sol-gel approach." Colloids and Surfaces A: Physicochemical and Engineering Aspects 262(1-3): 87-93. 
Ece, M. Ş. (2021). "Synthesis and characterization of activated carbon supported magnetic nanoparticles (Fe304/AC@SiO2@Sulfanilamide) and its application in removal of toluene and benzene." Colloids and Surfaces A: Physicochemical and Engineering Aspects 617: 126231.

Ece, M. Ş. (2021). "Synthesis and characterization of activated carbon supported magnetic nanoparticles (Fe304/AC@SiO2@Sulfanilamide) and its application in removal of toluene and benzene." Colloids and Surfaces A: Physicochemical and Engineering Aspects 617: 126231.

Ece, M. Ş., et al. (2020). "Development of Novel Fe304/AC@SiO2@1,4-DAAQ Magnetic Nanoparticles with Outstanding VOC Removal Capacity: Characterization, Optimization, Reusability, Kinetics, and Equilibrium Studies." Industrial \& Engineering Chemistry Research 59(48): 21106-21123.

Gad, Y. H. and A. M. Elbarbary (2021). "Radiation synthesis of Fe304/SiO2/glycidyl methacrylate/acrylonitrile nanocomposite for adsorption of basic violet 7 dye: Kinetic, isotherm, and thermodynamic study." Applied Organometallic Chemistry: e6258.

Ghorbani-Choghamarani, A., et al. (2016). "The first report on the eco-friendly synthesis of 5-substituted 1 H-tetrazoles in PEG catalyzed by Cu (ii) immobilized on Fe 30 4@ SiO 2@ I-arginine as a novel, recyclable and non-corrosive catalyst." RSC Advances 6(39): 32653-32660.

Jafarirad, S., et al. (2021). "Green and facile synthesis of gold/perlite nanocomposite using Allium Fistulosum L. for photothermal application." Photodiagnosis and Photodynamic Therapy: 102243.

Kalambate, P. K., et al. (2019). "Core@ shell nanomaterials based sensing devices: a review." TrAC Trends in Analytical Chemistry. 115: 147-161.

Kutluay, S. (2021). "Excellent adsorptive performance of novel magnetic nano-adsorbent functionalized with 8-hydroxyquinoline-5-sulfonic acid for the removal of volatile organic compounds (BTX) vapors." Fuel 287: 119691.

Liu, Z., et al. (2020). "Solvent-induced synthesis of hollow structured Fe304-based anode materials for high-performance Li-ion batteries." Journal of Materiomics 6(3): 485-493.

Majouli, A., et al. (2011). "Characterization of flat membrane support elaborated from local Moroccan Perlite." Desalination 277(1-3): 61-66.

Muthuselvi, C., et al. (2016). "Growth and Characterization of $\beta$-Sulfanilamide from Gel Medium." Journal of Chemical and Pharmaceutical Research 8(4): 858-866.

Sakamoto, Y., et al. (2004). "Three-Dimensional Structure of Large-Pore Mesoporous Cubic la 3 d Silica with Complementary Pores and Its Carbon Replica by Electron Crystallography." Angewandte Chemie International Edition 43(39): 5231-5234. 
Shen, L., et al. (2018). "Fe304 nanoparticles in targeted drug/gene delivery systems." Materials 11(2): 324.

Wang, X.-L., et al. (2010). "Synthesis of novel sulfanilamide-derived 1, 2, 3-triazoles and their evaluation for antibacterial and antifungal activities." European journal of medicinal chemistry. 45(10): 4631-4639.

Zhu, H.-Y., et al. (2011). "Adsorption removal of congo red onto magnetic cellulose/Fe304/activated carbon composite: Equilibrium, kinetic and thermodynamic studies." Chemical Engineering Journal 173(2): 494-502.

\section{Figures}

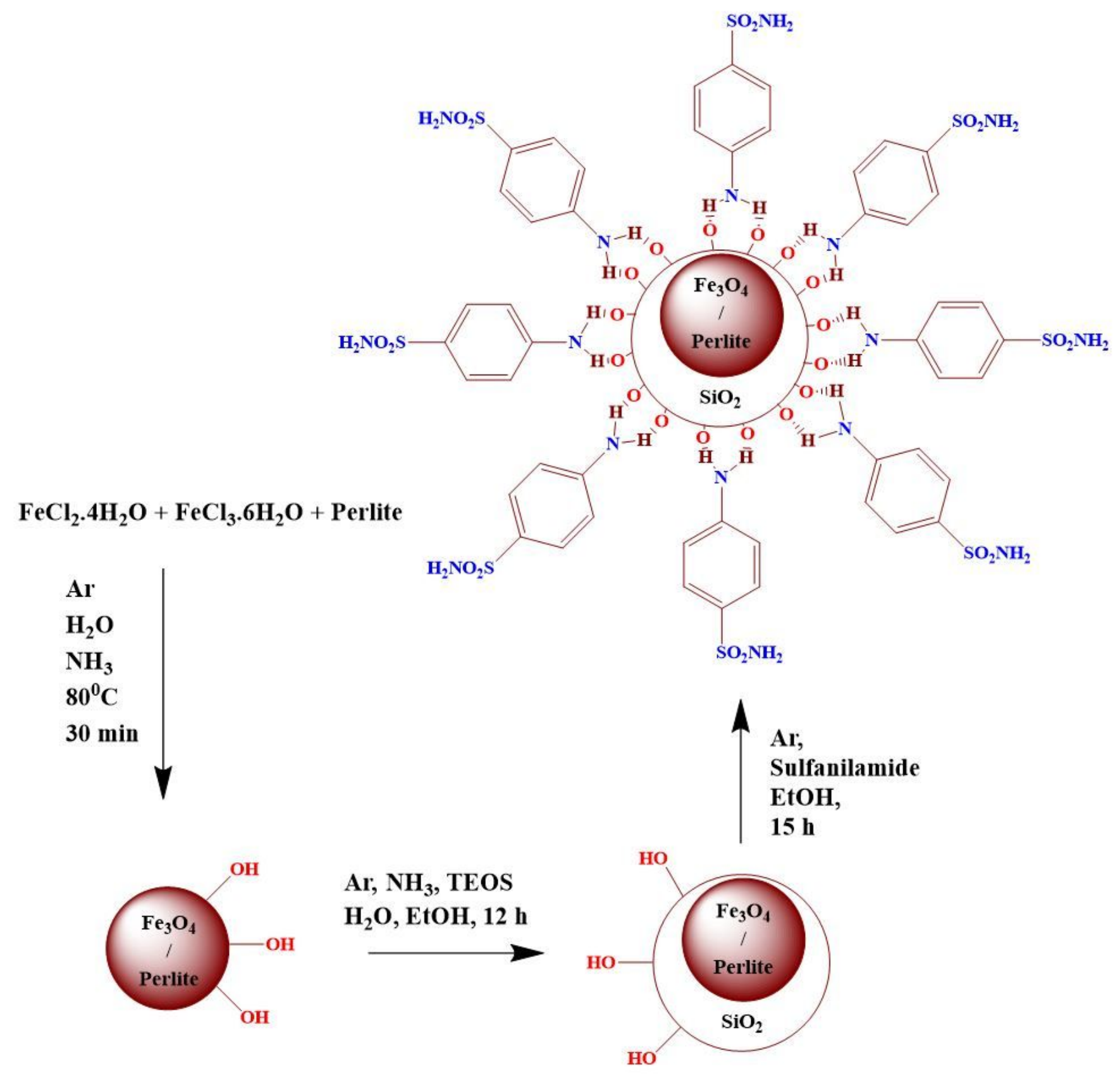


Figure 1

Schematic representation of fabrication processes of magnetic nano materials
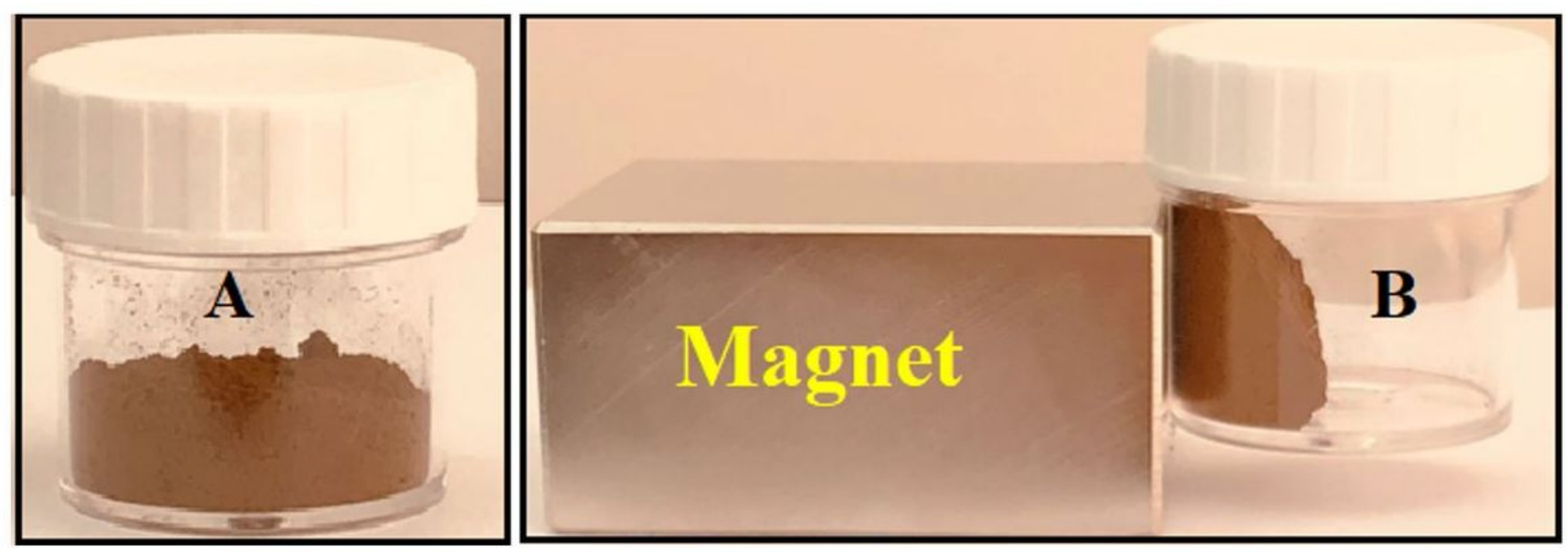

Figure 2

Magnetization abilities of magnetic nano materials before magnetization (a) and magnetization process (b) 

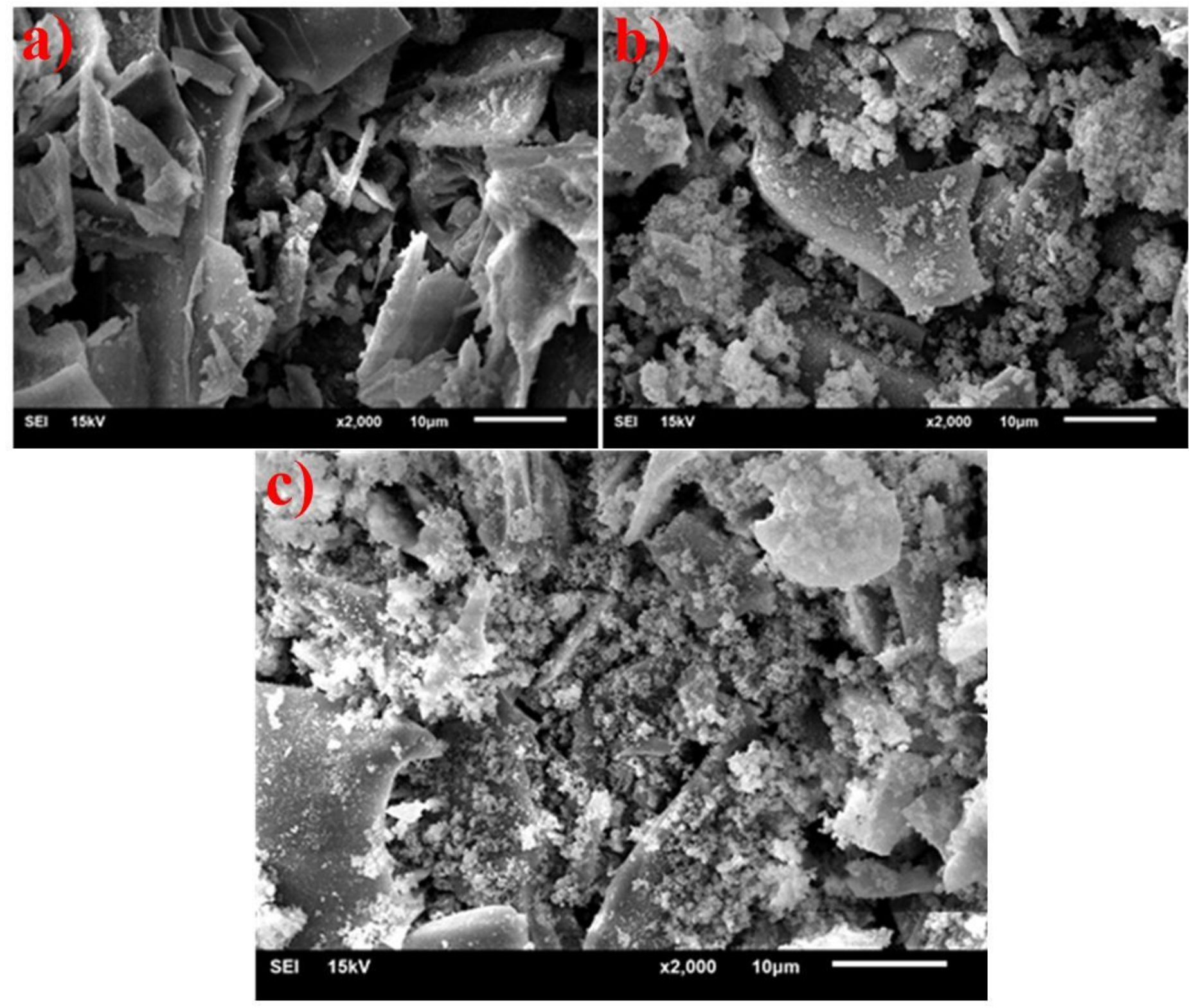

\section{Figure 3}

SEM images of Fe304/Perlite (a), Fe304/Perlite@SiO2 (b) and Fe304/Perlite@SiO2@Sulfanilamide (c) magnetic nano materials 


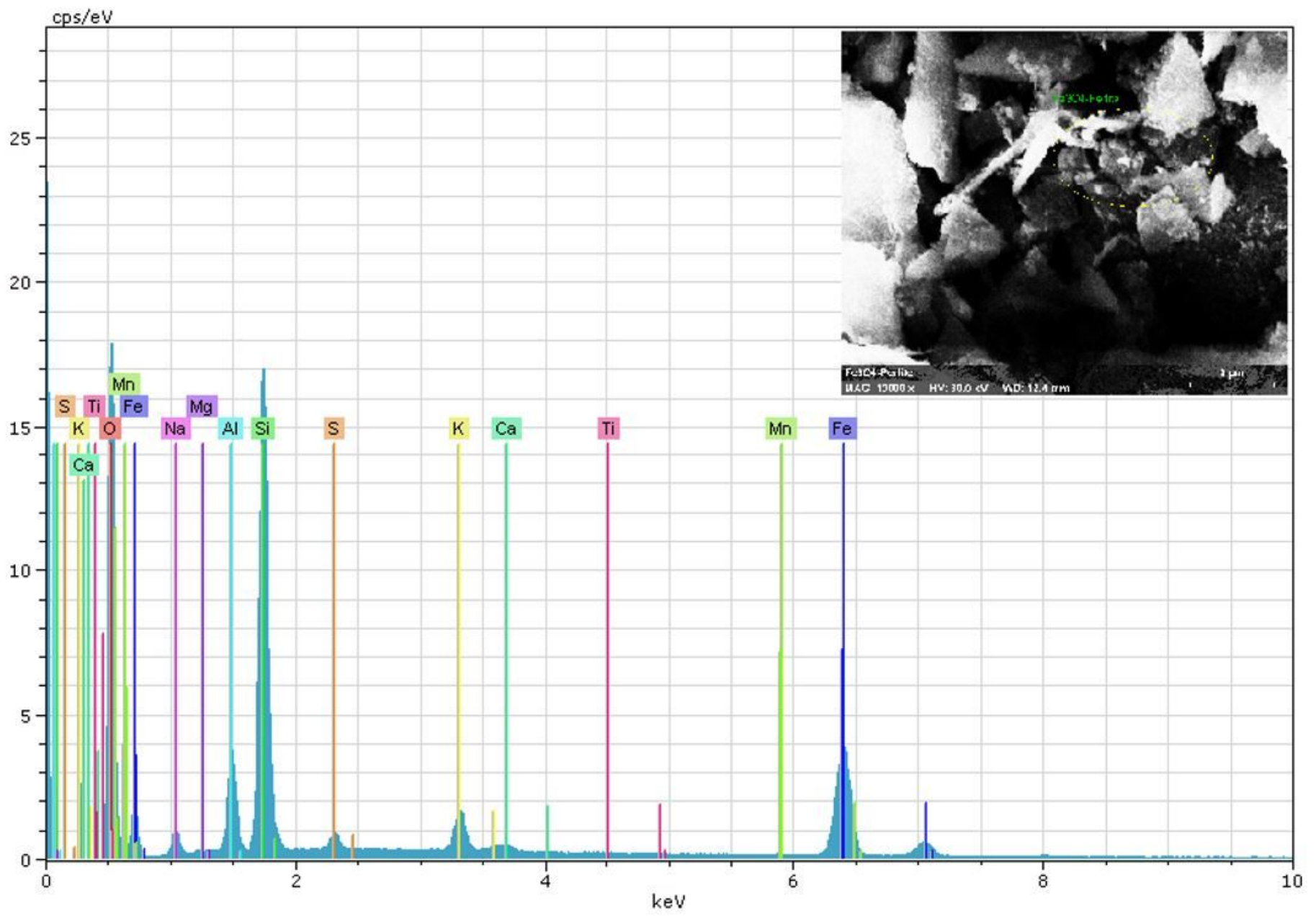

Figure 4

SEM-EDX analysis of Fe304/Perlite magnetic nano material 


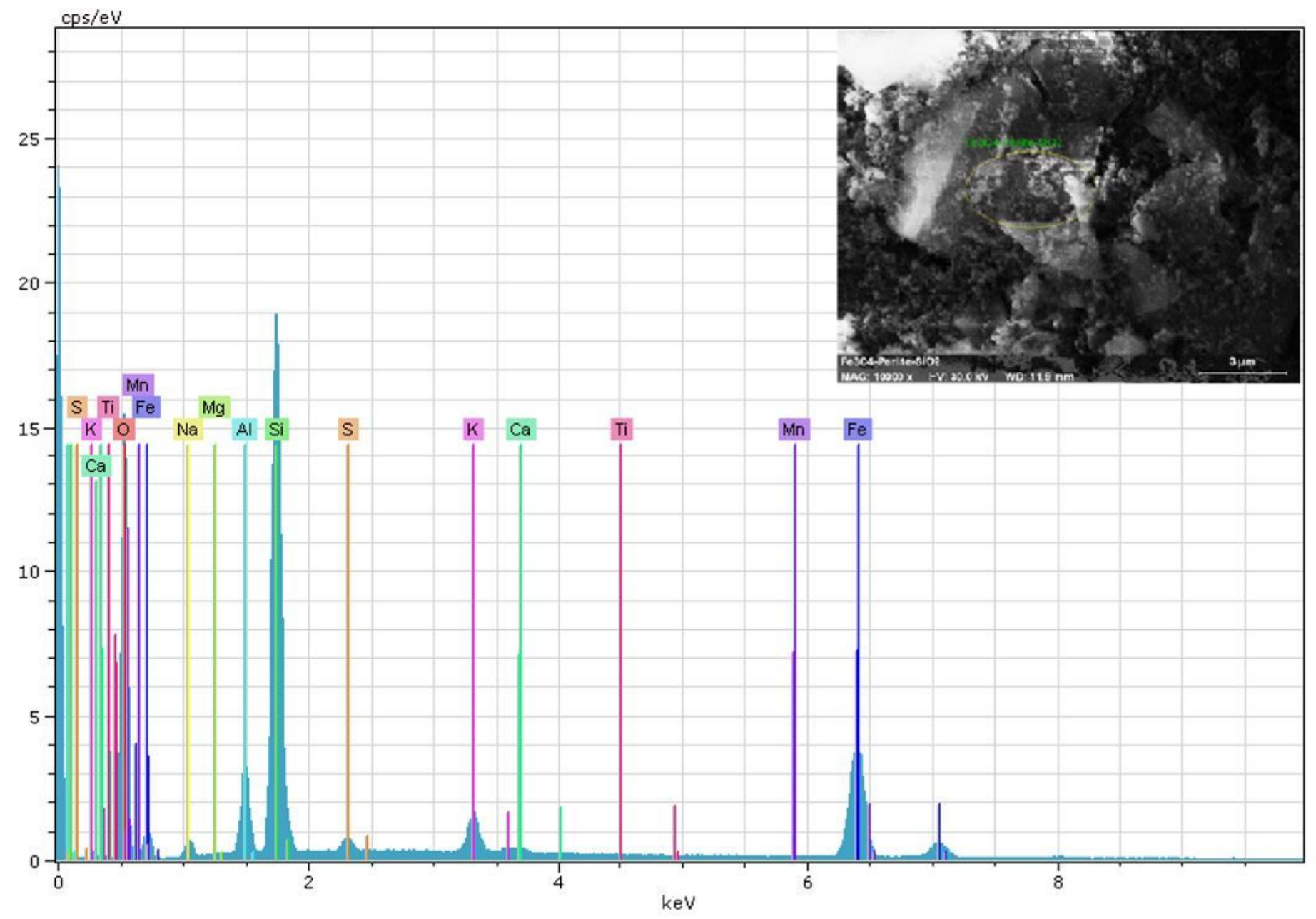

Figure 5

SEM-EDX analysis of Fe304/Perlite@SiO2 magnetic nano material 


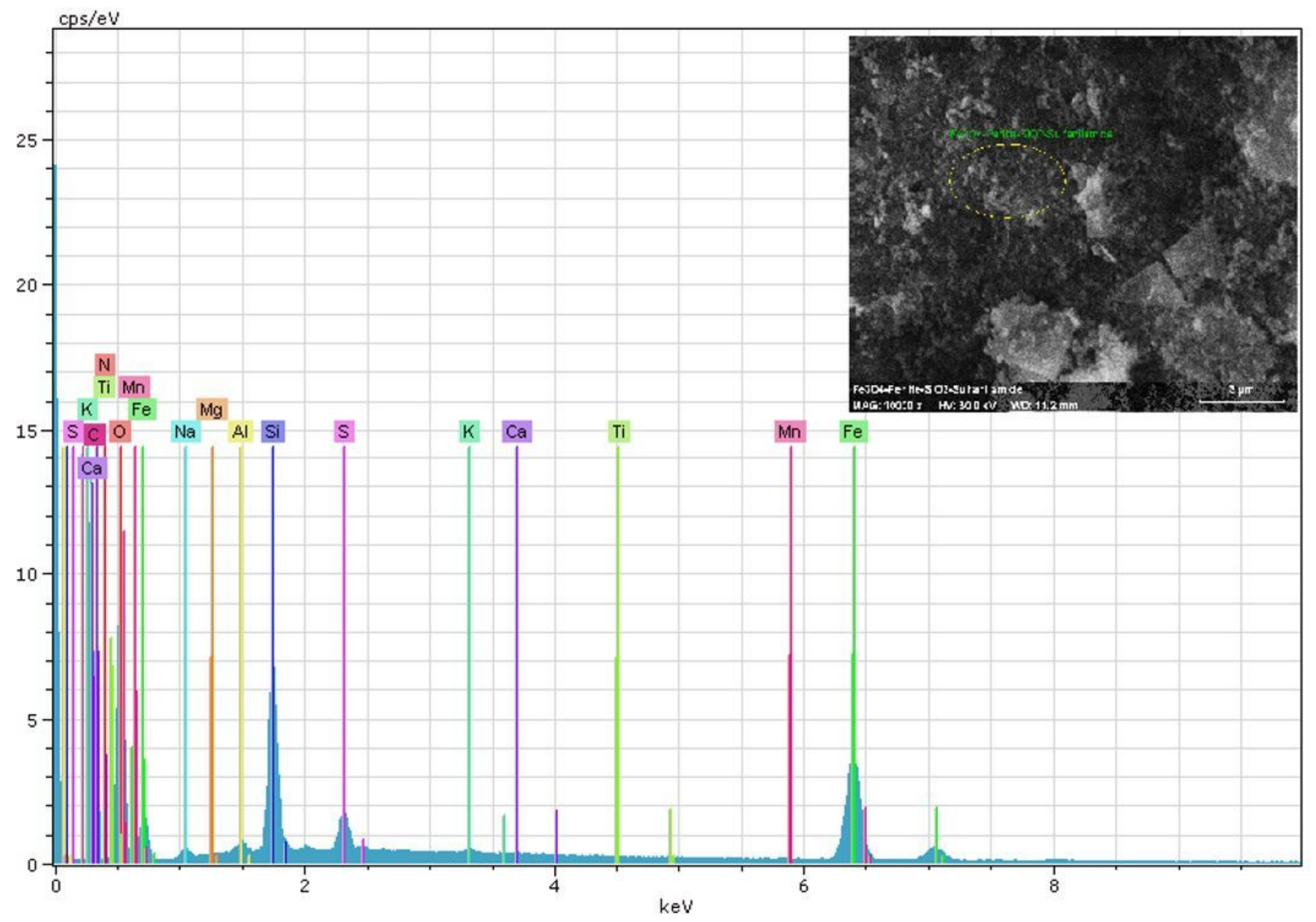

Figure 6

SEM-EDX analysis of Fe304/Perlite@SiO2@Sulfanilamide magnetic nano material 


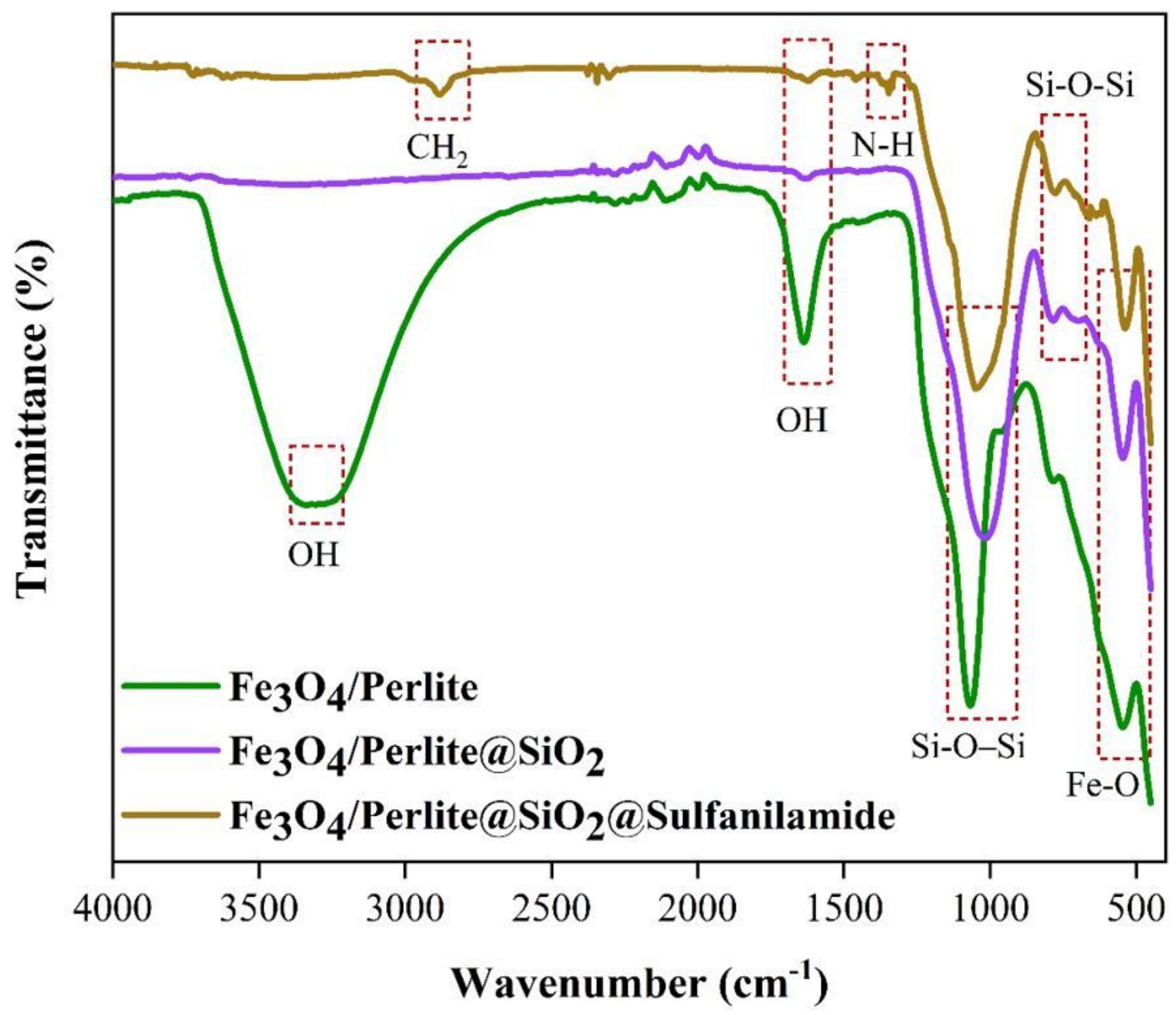

Figure 7

The FTIR spectra of Fe304/Perlite, Fe304/Perlite@SiO2 and Fe304/Perlite@SiO2@Sulfanilamide magnetic nano materials 


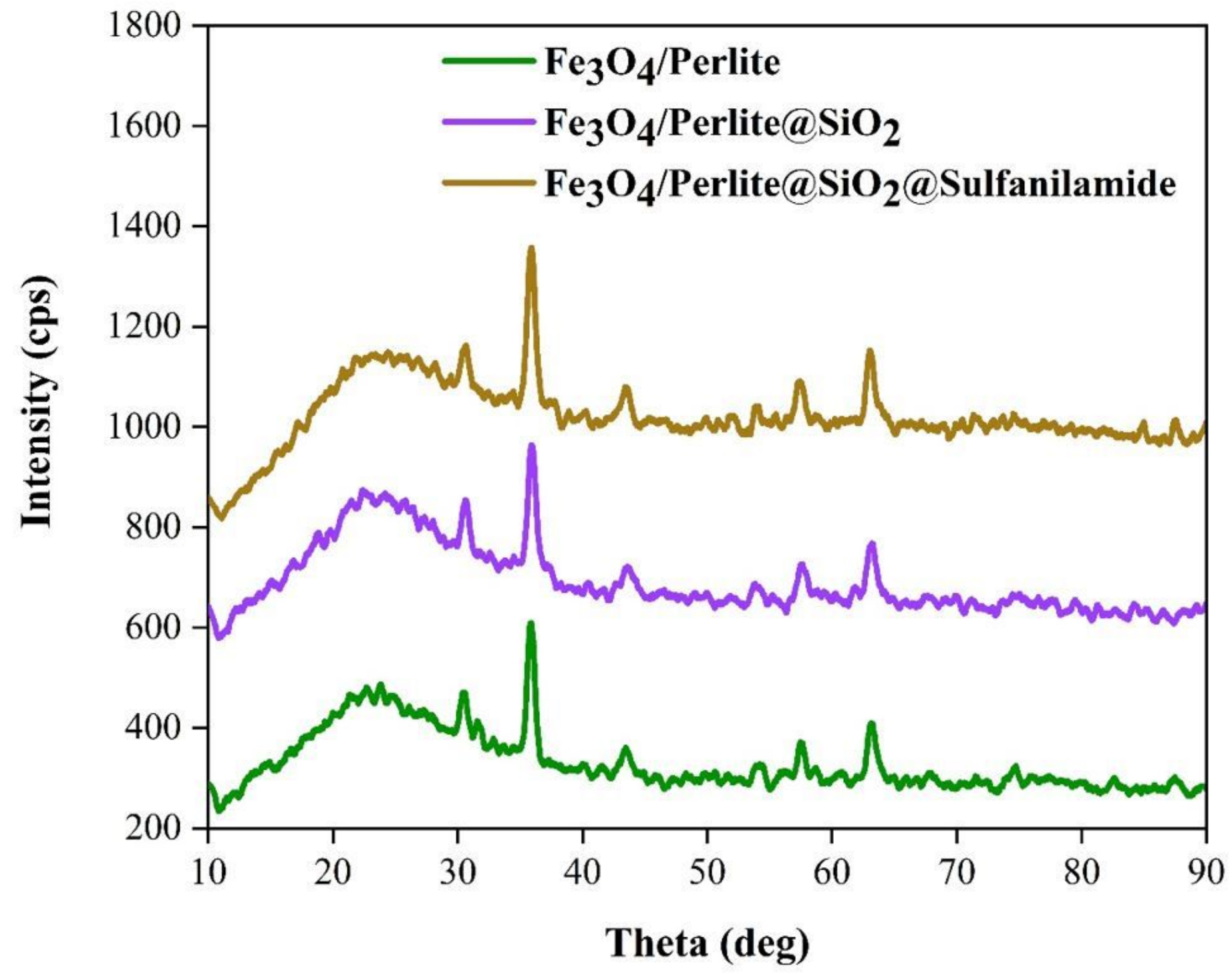

Figure 8

The XRD patterns of Fe304/Perlite,Fe304/Perlite@SiO2 and Fe304/Perlite@SiO2@Sulfanilamide magnetic nano materials 

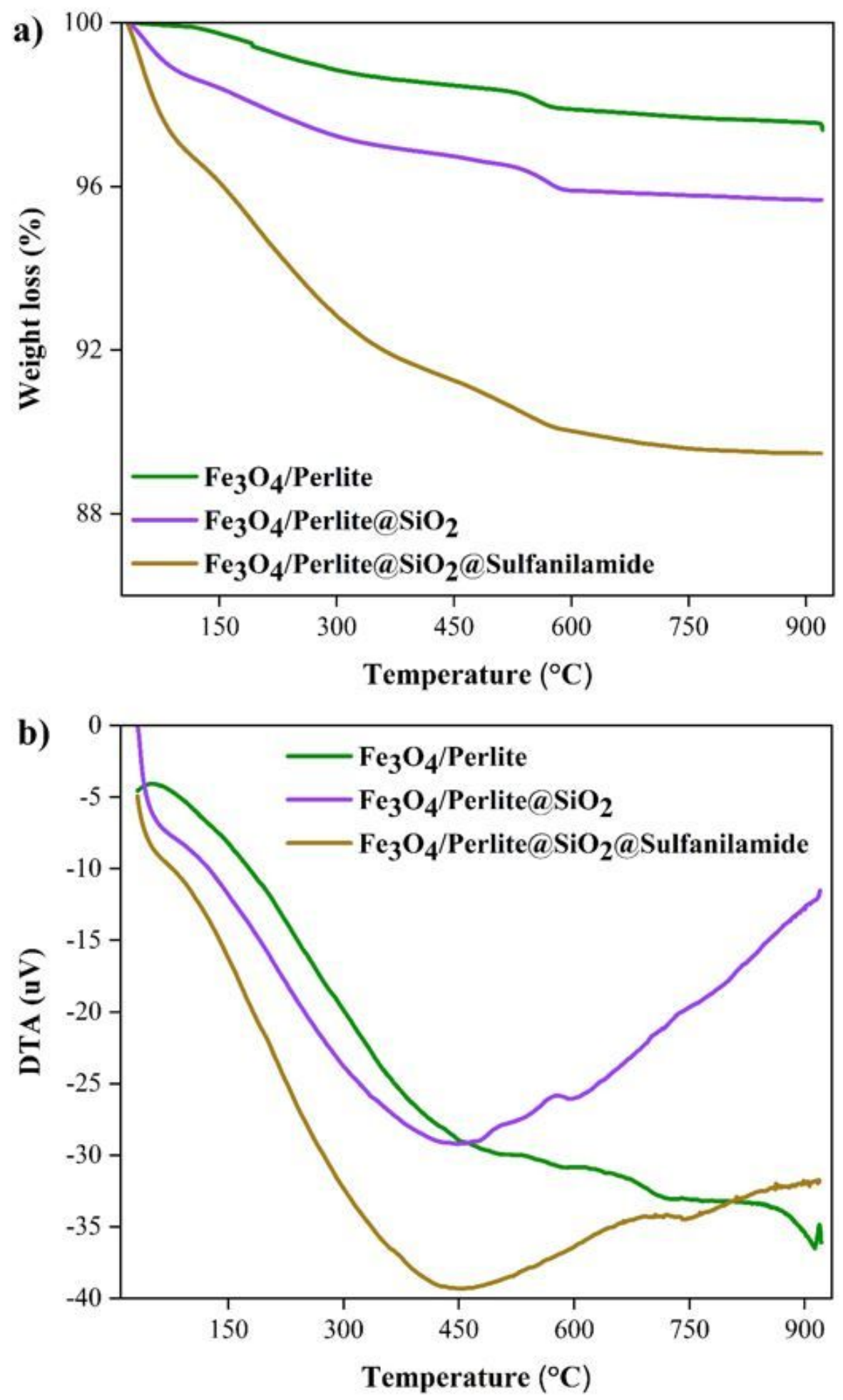

Figure 9

TGA (a) and DTA (b) of Fe304/Perlite, Fe304/Perlite@SiO2 and Fe304/Perlite@SiO2@Sulfanilamide magnetic nano materials 


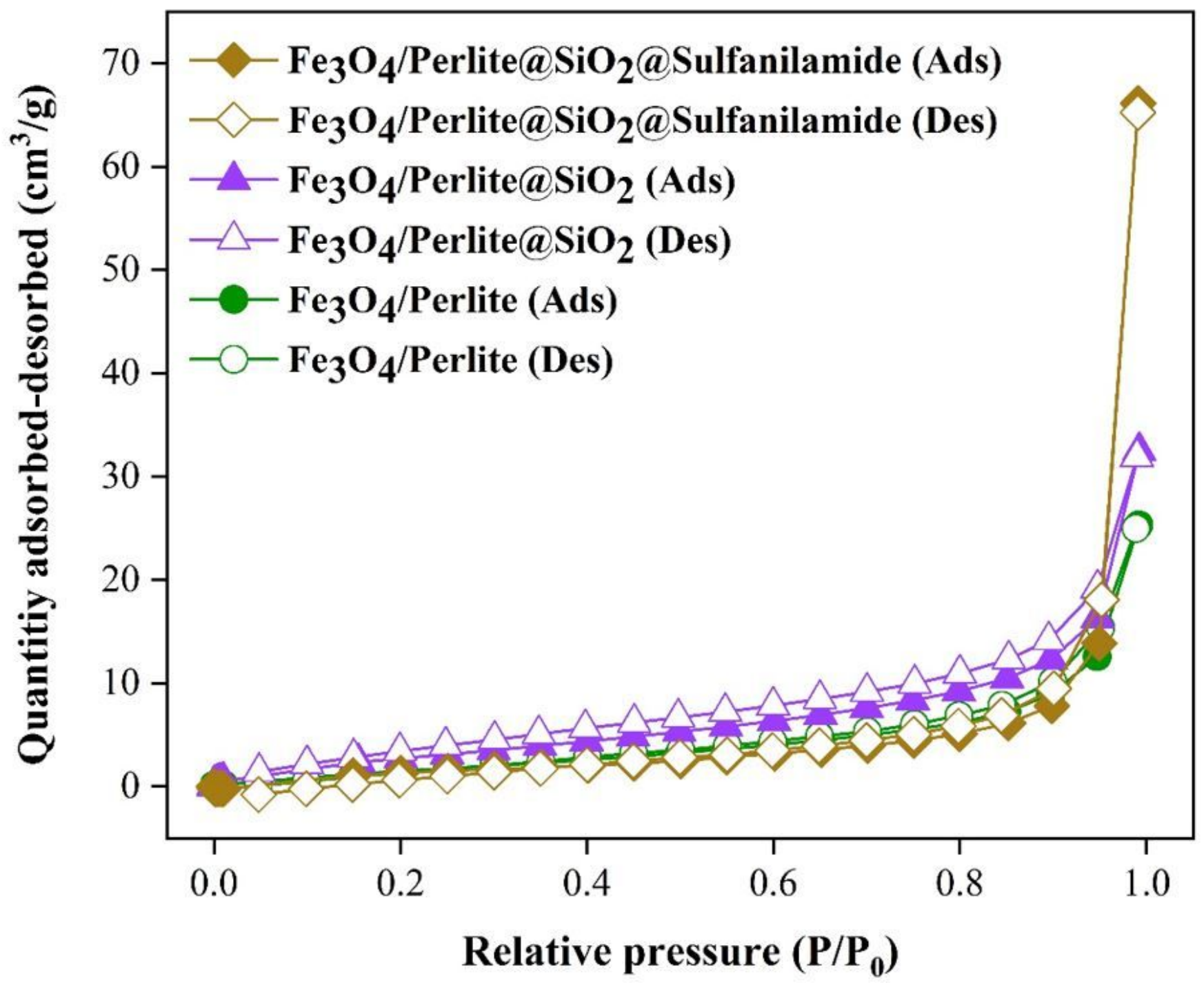

Figure 10

N2 adsorption-desorption isotherms of Fe304/Perlite, Fe304/Perlite@SiO2 and Fe304/Perlite@Si02@Sulfanilamide magnetic nano materials 


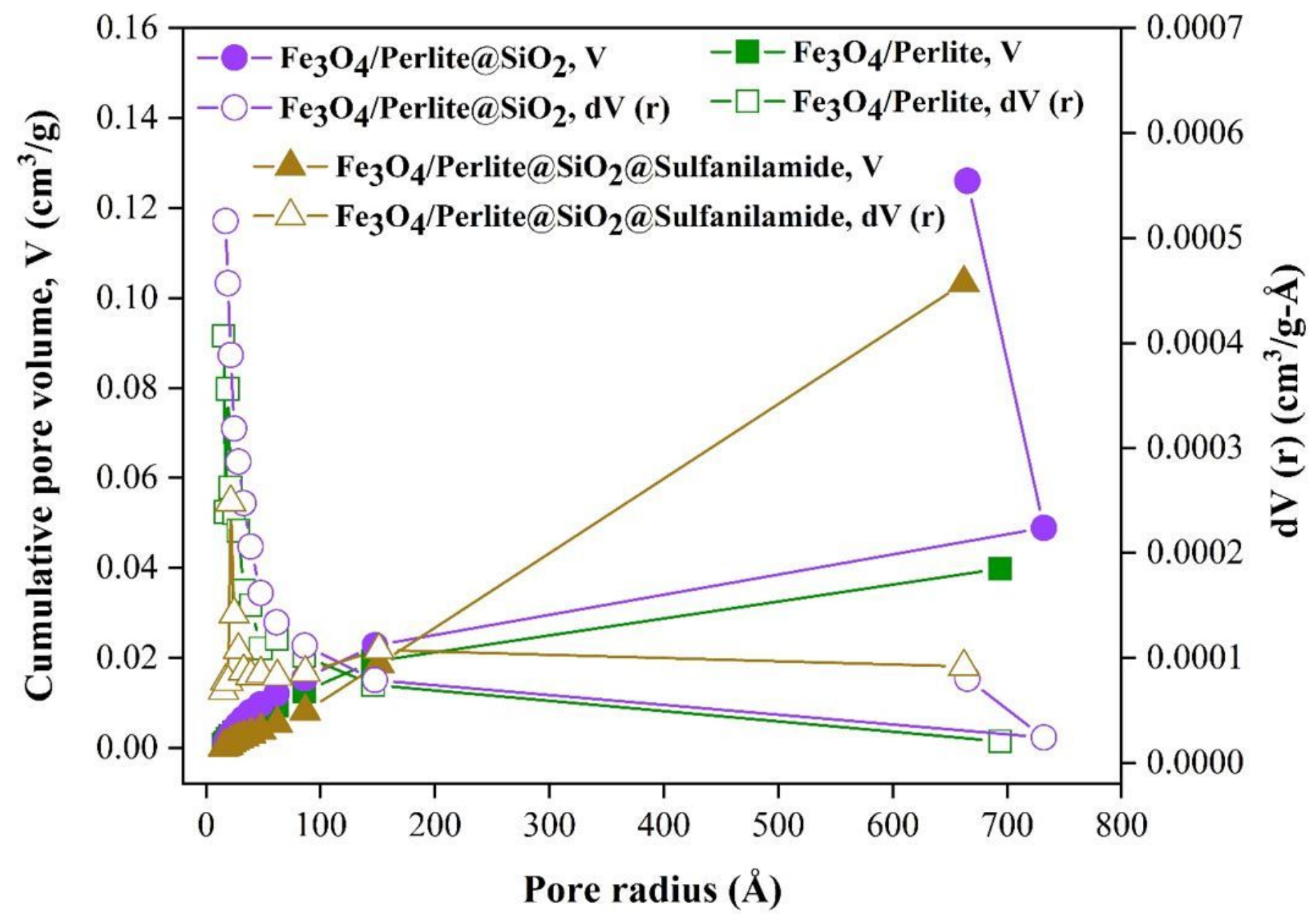

Figure 11

Pore size distributions of $0.5 \sim 680 \AA$ calculated by the BJH method of the Fe304/Perlite, Fe304/Perlite@SiO2 and Fe304/Perlite@SiO2@Sulfanilamide magnetic nano materials 


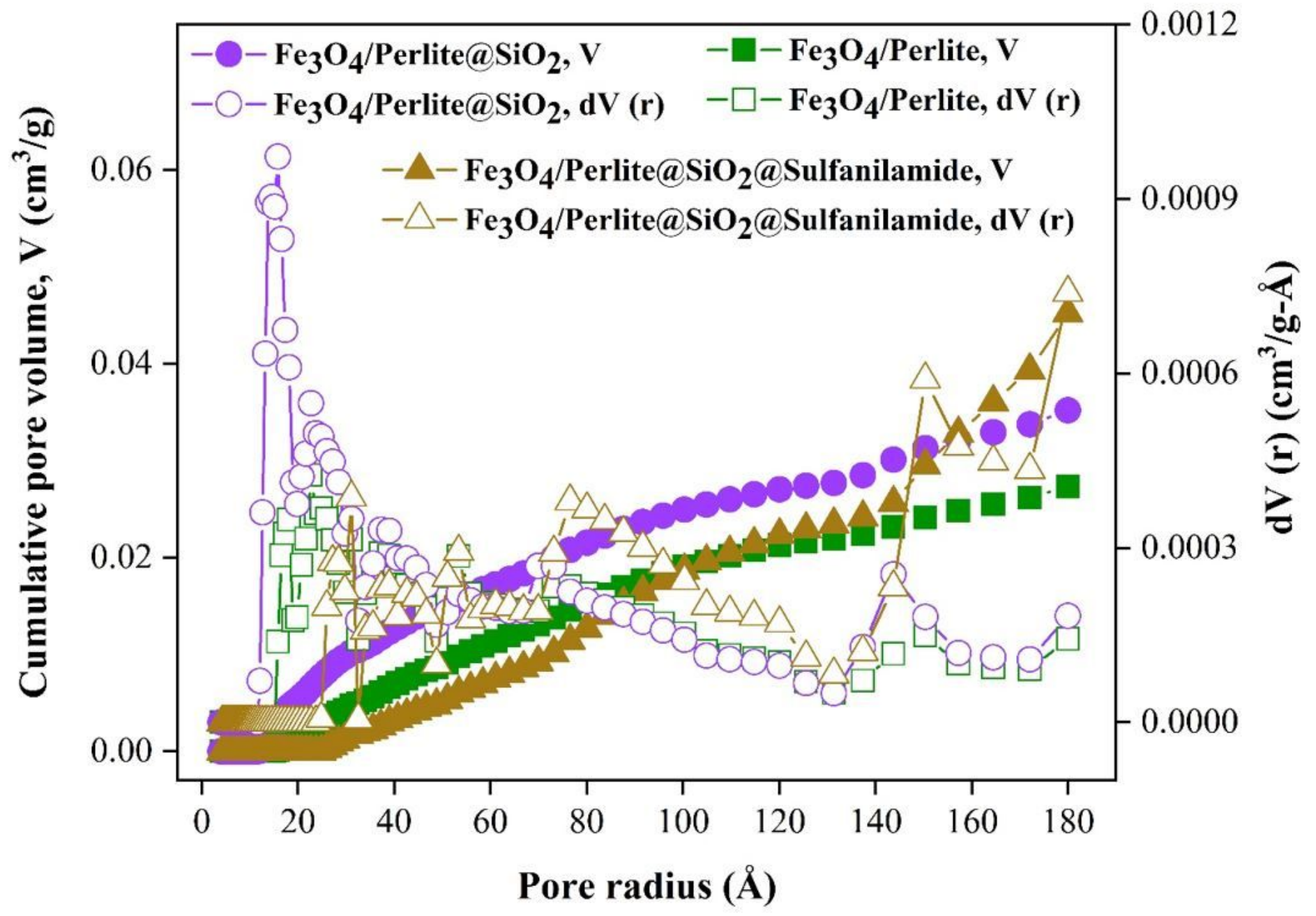

Figure 12

Pore size distributions of $0.5 \sim 180 \AA$ calculated by the DFT method of the Fe304/Perlite, Fe304/Perlite@SiO2 and Fe304/Perlite@SiO2@Sulfanilamide magnetic nano materials 

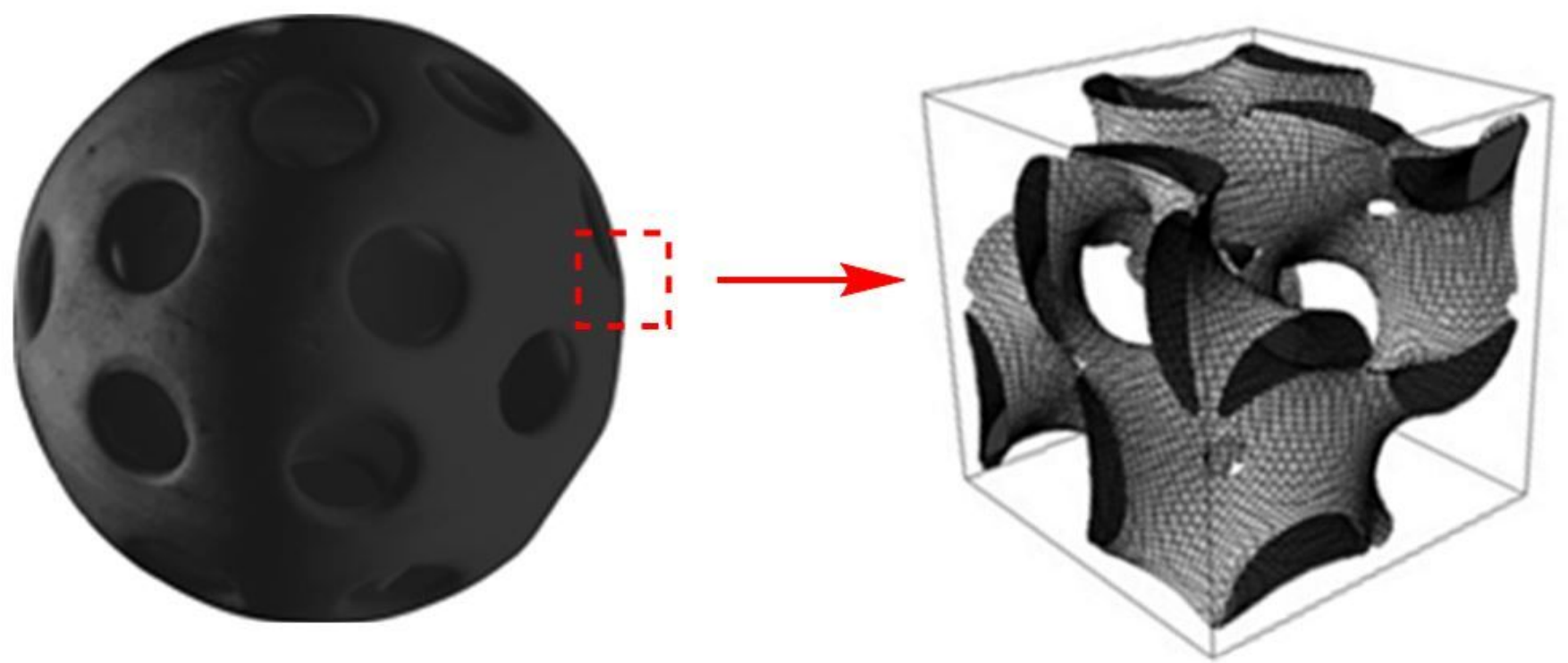

Figure 13

Predicted 3-dimensional structure of magnetic nanomaterial with cavity

\section{Supplementary Files}

This is a list of supplementary files associated with this preprint. Click to download.

- graphicsabstract.jpg 